\title{
Sex and Age Comparisons in Neuromuscular And Biomechanical Characteristics of the Knee in Young Athletes
}

\author{
Erin R Pletcher, PhD, ATC, CSCS $^{1}$, Travis J Dekker, MD², Scott M Lephart, PhD ${ }^{3}$, Tim C Sell, PhD, PT $^{4}$ \\ ${ }^{1}$ Department of Exercise Science, Thomas Jefferson University, ${ }^{2}$ Department of Orthopaedic Surgery, Duke University Medical Center, ${ }^{3}$ College of \\ Health Sciences, University of Kentucky, ${ }^{4}$ Atrium Health Musculoskeletal Institute \\ Keywords: static balance, neuromuscular control, lower extremity biomechanics, injury prevention, adolescent athlete
}

https://doi.org/10.26603/001c.21358

\section{International Journal of Sports Physical Therapy}

Vol. 16, Issue 2, 2021

\section{Background}

The identification of risk factors for injury is a key step for musculoskeletal injury prevention in youth sports. Not identifying and correcting for injury risk factors may result in lost opportunity for athletic development. Physical maturation and sex affect these characteristics, which may indicate the need for both age and sex-based injury prevention programs.

\section{Hypothesis/Purpose}

This study examined age and sex differences in knee strength, static balance, jump height, and lower extremity landing biomechanics in school- and high school-age athletes.

\section{Study Design}

Cross-sectional

\section{Methods}

Forty healthy school aged ( $10.8 \pm 0.8$ yrs) and forty high school ( $16.8 \pm 0.8$ yrs) athletes completed isokinetic knee flexion and extension strength tests, single-leg static balance and single-leg vertical stop jump tasks.

\section{Results}

High school athletes were significantly stronger ( $\sim 67 \%$ and $35 \%$ stronger for males and females, respectively) and jumped higher (regardless of sex) compared to school age athletes. High school males had worse balance ( 28\%) compared to their younger counterparts. High school females had lower strength ( 23\%) compared to males but had better balance ( $46 \%)$. Conclusion: Maturation had different effects on the variables analyzed and sex differences were mainly observed after maturation. These differences may be minimized through appropriate age and sex specific training programs.

\section{Levels of Evidence}

3a

\section{Clinical Relevance}

Neuromuscular and biomechanical differences between sex and age groups should be accounted for in injury prevention and rehabilitation. Inadequate training may be a primary factor contributing to injuries in a young athletic population. When designing

\footnotetext{
a Corresponding author:

Erin Pletcher

Department of Exercise Science

Thomas Jefferson University

Philadelphia, PA 19144

Erin.Pletcher@jefferson.edu

Phone: 215-951-2732
} 
training programs for long term athlete development, programs should be dependent on decrements seen at specific time points throughout maturation.

What is known about the subject: Generally, both males and females get stronger and jump higher as they get older but the results comparing balance and biomechanics between genders or across age groups have been mixed.

What this study adds to existing knowledge: The current study looks at multiple neuromuscular and biomechanical variables in male and female participants at different maturation statuses. The current data supports the significant changes observed in strength and jump height, as both genders age, but the data also demonstrates significant differences in balance between age groups in males and between genders in balance and knee flexion angles.

\section{INTRODUCTION}

There are an estimated 30 to 45 million youth, ages 6 to 18 years, participating in athletics in the United States and approximately one third of these youth athletes seek attention for sport related injuries. ${ }^{1}$ The number of injuries in adolescents has been on the rise, causing concern for long term problems with compromised quality of life and increased risk of further injury. ${ }^{2}$ Injuries to the anterior cruciate ligament (ACL) often occur between 16-18 years of age, ${ }^{3}$ however, the frequency of injury between the ages of 11-12 years has been steadily increasing. ${ }^{3}$ Sex differences in injury rates have been reported across a wide range of sports, indicating a need for intervention at a young age. At the high school setting, ACL injury rates for females have been shown to be higher than males (IRR 2.30), with the largest difference in basketball athletes (IRR 3.68). ${ }^{4} \mathrm{~A}$ higher female ACL injury rate was also seen at the collegiate level, with females higher than males (IRR 2.49), and the greatest difference being between baseball and softball athletes (ITT 6.61). ${ }^{4}$

Previous literature has demonstrated decreased neuromuscular control in females compared to males. ${ }^{5}$ Multiple factors may predispose adolescents to injury, before including extrinsic mechanisms of injury in sport. Risk factors for injury in youth include lack of muscular strength, ${ }^{6}$ balance, ${ }^{7}$ decreased knee flexion moment, ${ }^{8}$ and increased knee valgus moment. ${ }^{9}$ To counteract these risk factors, the optimal age to introduce specific training interventions has been debated. During adolescence, males and females experience skeletal, neuroendocrine and sexual maturation developments that make injury prevention strategies and training prescription a complex process. ${ }^{10}$ There has been limited success of athlete development programs; as athlete development should be based on individually unique and constantly changing characteristics, including the demands of normal physical growth, biological maturation, behavioral development and their interactions. ${ }^{11}$ Challenges in factors associated with maturation and sex must be considered when creating guidelines to develop healthy, resilient young athletes.

Athletic development is multidimensional and difficult to assess in youth, as trajectories from novice to elite can vary greatly among athletes. The mechanism for sex differences in lower extremity injury rates remains unknown despite a multitude of kinematic and kinetic studies. It is essential to identify sex related physical and physiological differences that occur because of maturation, as these may help identify risk factors that lead to injury rate differences between sexes.

Factors underlying sex differences in injury rate have previously been categorized into several general theories: anatomical, hormonal and biomechanical. ${ }^{12}$ Previous literature has individually examined maturation's effect on gender differences in strength, ${ }^{13}$ static balance, ${ }^{14}$ knee kinematics, ${ }^{15}$ and vertical jump. ${ }^{16}$ However, previous research has not examined multiple risk factors together in one participant population. Understanding associations in injury risk factors and injury patterns play an important role in the development of injury prevention strategies.

The purpose of this study was to examine and compare strength, static balance, jump height, and landing kinematics characteristics in school age and high school athletes based on sex and age. It was hypothesized that (1) as age increases, strength and performance of both sexes will improve; furthermore, (2) knee joint flexion angles measured at initial contact and peak flexion will decrease at the high school level. Additionally, (3) males will perform better on strength, biomechanics, and performance than females at the high school level, while (4) females will perform better with balance. Recognizing neuromuscular and biomechanical differences between sexes at different ages will help better develop healthy, resilient youth athletes.

\section{METHODS}

\section{PARTICIPANTS}

Forty healthy school aged (10.8 \pm 0.8 yrs) and forty high school (16.8 \pm 0.8 yrs) athletes with a similar distribution of males and females within each group participated in the study. Self-assessed Tanner Scale stage was used to ensure participants fell into one of two categories: prepubertal (stage 1) for school aged athletes or post pubertal (stage 4 of 4) for high school aged. All participants participated in organized sports that required jumping, cutting and landing, at least three times per week. Injury prevention programs have been shown to induce favorable neuromuscular and biomechanical changes, ${ }^{17}$ therefore all athletes in this study did not participate in any form of injury prevention training at any time before or during data collection. Participants were excluded if they had any self-reported history of serious lower extremity musculoskeletal injury (such as ligament rupture), musculoskeletal injury within the last six months or any history of rheumatological disorder, cerebral vascular accident, peripheral nerve disorder, or any other disorder that interferes with sensory input and/or motor function. All participants were informed of testing proce- 
dures and provided written consent (or assent as appropriate) that was approved by the University's Institutional Review Board. All testing was conducted at the Neuromuscular Research Laboratory within the University. Reliability of testing procedures has been established previously. ${ }^{18}$

\section{INSTRUMENTATION}

Isokinetic strength was collected for the knee flexors and extensors utilizing the Biodex System 3 Multi-Joint testing and Rehabilitation System (Biodex Medical Inc., Shirley, NY). Ground reaction forces during static balance testing and the single-leg stop-jump task were collected utilizing two force plates (Kistler Corporation, Worthington, $\mathrm{OH}$; Model \#4060-1011000). Ground reaction force data was collected at $1200 \mathrm{~Hz}$ during the single-leg stop-jump task and at $100 \mathrm{~Hz}$ during the balance testing. Three-dimensional coordinate data from 15 retroreflective markers during the single-leg stop-jump task were collected and calculated using a 3D optical capture system (Peak Performance Technologies, Inc., Englewood, CO). This motion analysis system includes six high speed $(120 \mathrm{~Hz})$ optical cameras (Pulnix Industrial Product Division, Sunnyvale, CA) instrumented and synchronized using Peak Motus software (version 7.2, Peak Performance Technologies, Inc., Englewood, $\mathrm{CO})$.

\section{PROCEDURES}

All participants completed balance assessments first, followed by strength then single-leg vertical stop jump task. Lower extremity segment lengths and joint widths of each participant were taken of the lower extremity in addition to body mass (kilograms) and standing height (meters). The Biodex System was used to test dominant leg muscle strength of the quadriceps and hamstrings musculature during an isokinetic knee flexion and extension test. ${ }^{19}$ Leg dominance was defined as the leg a participant would naturally use to kick a soccer ball. Participants were secured in the chair with straps to isolate the tested movement, range of motion was set to allow for zero to 90 degrees of rotation (based on the attachment arm); and provided a warm-up session of three repetitions at 50\% of maximum effort and three repetitions at $100 \%$ of maximum effort. Participants were instructed to give maximum effort throughout the entire test. Five maximal quadriceps and hamstring contractions at $60^{\circ} / \mathrm{sec}$ were performed with one minute of rest between all sessions. ${ }^{19}$

Single-leg balance testing was performed bilaterally for each participant with eyes open and closed. Five trials (ten seconds each) for each condition per leg were collected. Order of testing (by condition) was determined by simple randomization prior to data collection and participants were given one practice trial for each condition and for each leg prior to testing. The testing position was unilateral stance with the untested leg flexed slightly at the hip and the knee with hands on hips. Participants were instructed to remain "as still as possible" throughout each trial and to regain the test position as quickly as possible if there is a loss of balance. ${ }^{20}$ Touchdowns on the force plate were acceptable, as they added to the variability in balance measurement. Trials

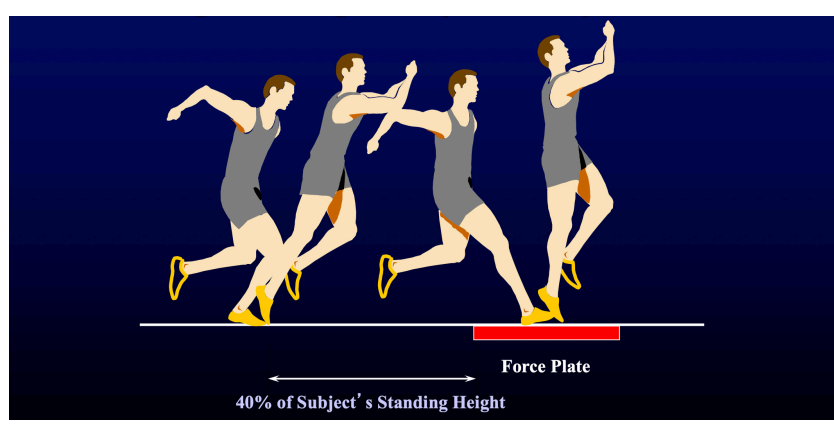

Figure 1: Single-leg vertical stop jump task

were excluded if the participant touched down off the force plate because it would not be contributing to the force-platform measure. ${ }^{21}$

Fifteen retroreflective markers were utilized for data collection of 3D coordinate data during the single-leg vertical stop-jump task. ${ }^{22}$ During the single-leg vertical stop jump task, retroreflective markers were placed bilaterally over the second metatarsal head, posterior aspect of the heel, lateral malleolus, femoral epicondyle, anterior superior iliac spine, and the L5-S1 disc space. Four other markers were attached to wands (approximate length $0.07 \mathrm{~m}$ ) and secured bilaterally with Velcro straps and athletic tape to the lateral aspect of the participant's thigh and shank.

The single-leg vertical stop jump task consisted of the following: 1) initial starting point measured as $40 \%$ of the participant's height from the edge of the force plates, 2) jump with a single-leg landing on a force plate, 3) immediate jump for maximum vertical height following landing on the force plate, and 4) landing in approximately the same location from which the maximal jump was initiated (Figure 1). ${ }^{23}$ Participants were given a verbal description, visual demonstration, and five practice trials on each leg in order to assure familiarity with the task. The first five good trials were used for data processing. A good trial was defined as a trial during which the participant performed the task with the proper technique, landed successfully on the force plate and did not touch down outside the force plate.

\section{DATA REDUCTION}

The Biodex Advantage Software v3.0 was used to calculate the absolute peak torque and average peak torque normalized to body weight (\%BW) (mass $\mathrm{x}$ gravity) for the isokinetic strength test of the quadriceps and hamstrings for each leg. Additionally, the hamstring:quadriceps ratio was calculated for absolute peak torque and peak torque normalized to body weight. Single leg balance ground reaction force data were processed through a custom Matlab (MathWorks, Natick, MA) script. Ground reaction force data were passed through a zero-lag 4th order low pass Butterworth filter with a $100 \mathrm{~Hz}$ cutoff frequency. ${ }^{22}$ The standard deviation (SD) for each component ground reaction force (anterior-posterior, medial-lateral and vertical ground reaction force) was calculated during the entire trial and then averaged across all five static balance trials. ${ }^{20,21}$ Lower extremity kinematic and kinetic data of the single-leg vertical stop jump was calculated using Kinecalc module of the Peak Mo- 
Table 1: Subject Demographics by Sex

\begin{tabular}{|c|c|c|c|c|c|c|c|c|}
\hline & & & & & \multicolumn{4}{|c|}{ Pairwise Comparison ( $p$-values) } \\
\hline & \multicolumn{2}{|c|}{ Male $(n=82)$} & \multicolumn{2}{|c|}{ Female $(n=78)$} & \multicolumn{2}{|c|}{ Sex Comparisons } & \multicolumn{2}{|c|}{ Age Comparisons } \\
\hline & $\begin{array}{l}\text { School age } \\
\quad(n=42)\end{array}$ & $\begin{array}{l}\text { High } \\
\text { school } \\
(n=40)\end{array}$ & $\begin{array}{l}\text { School age } \\
\quad(n=38)\end{array}$ & $\begin{array}{l}\text { High } \\
\text { school } \\
(n=40)\end{array}$ & $\begin{array}{l}\text { School } \\
\text { age }\end{array}$ & $\begin{array}{l}\text { High } \\
\text { school }\end{array}$ & Males & Females \\
\hline $\begin{array}{l}\text { Age } \\
\text { (yrs) }\end{array}$ & $\begin{array}{c}11.00 \pm \\
0.77\end{array}$ & $\begin{array}{c}17.00 \pm \\
0.78\end{array}$ & $\begin{array}{c}10.47 \pm \\
0.60\end{array}$ & $\begin{array}{c}16.60 \pm \\
0.67\end{array}$ & 0.002 & 0.020 & $<0.001$ & $<0.001$ \\
\hline $\begin{array}{l}\text { Height } \\
\text { (m) }\end{array}$ & $\begin{array}{c}1.52 \pm \\
0.11\end{array}$ & $1.79 \pm 0.08$ & $\begin{array}{l}1.48 \pm \\
0.08\end{array}$ & $1.67 \pm 0.08$ & 0.101 & $<0.001$ & $<0.001$ & $<0.001$ \\
\hline $\begin{array}{l}\text { Weight } \\
\text { (kg) }\end{array}$ & $\begin{array}{c}44.8 \pm \\
12.3\end{array}$ & $74.3 \pm 6.2$ & $\begin{array}{c}40.2 \pm \\
10.2\end{array}$ & $\begin{array}{c}61.57 \pm \\
8.33\end{array}$ & 0.093 & $<0.001$ & $<0.001$ & $<0.001$ \\
\hline \multicolumn{3}{|c|}{ mean $\pm s d$} & \multicolumn{6}{|c|}{ Significance set at 0.05 level } \\
\hline
\end{tabular}

tus software package (Peak Performance Technologies, Inc., Englewood, CO). Vertical jump height was measured as the difference between the sacral marker during the static trial and the maximum during jump trial, and then calculated as percent body height (\%BH). Kinematic data were calculated as previously published on reactive tasks. ${ }^{22}$ Raw analog data from the force plates were used to calculate the ground reaction force data for each vertical stop jump trial. The ground reaction force data were used to calculate the peak vertical ground reaction force during the initial stance phase of the single-leg stop-jump task. This point was then identified in the joint kinematic data to determine knee flexion/extension and the knee valgus/varus angle at initial contact. Vertical stop jump peak vertical ground reaction force data were then normalized to percent body weight. Data were averaged across five trials.

\section{STATISTICAL METHODS}

All statistical analysis was performed using SPSS version 21.0 (SPSS Inc., Chicago, IL). Analyses consisted of: descriptive statistics (mean, standard deviation) for each age group and sex were calculated; independent t-tests for comparison of demographic data; two-way analysis of variance (ANOVA) to examine the effect of age group and sex on each variable; and multiple pairwise comparisons at the level of the interaction to assess differences between age group and sex. Additionally, Cohen's $d$ effect size was calculated to assess the magnitude of difference between each pairwise comparison.

\section{RESULTS}

There were significant differences between sexes for high school athletes in height $(p<0.001)$ and weight $(p<0.001)$
(Table 1), with males being taller and heavier.

At the high school age, males were shown to be stronger than females in knee flexion and extension strength, both for average peak torque $(\mathrm{p}<0.001)$ and relative to body weight $(\mathrm{p}<0.001)$. (Table 2) High school aged athletes, compared to school age athletes, were stronger in knee flexion and extension strength, both for average peak torque $(p<0.001)$ and relative to body weight $(p<0.001)$. High school aged athletes had a larger hamstring:quadriceps ratio relative to body weight (males $\mathrm{p}=0.031$, females $\mathrm{p}=0.046$ ). Female high school ages athletes had a larger absolute peak torque hamstring:quadriceps ratio $(\mathrm{p}=0.041)$ (Table 2).

School aged females demonstrated significantly better static balance than school aged males in the anterior-posterior (AP) $(\mathrm{p}=0.047)$ and the medial-lateral (ML) $(\mathrm{p}=0.018)$ directions with eyes opened and ML direction with eyes closed $(\mathrm{p}=0.027)$. High school aged females demonstrated better static balance than high school aged males, in all directions, with eyes opened and closed. (Table 3) Males exhibited better static balance at the school age, compared to high school, in the AP and ML directions with both eyes opened ( $\mathrm{p}=0.001, \mathrm{p}<0.001$, respectively) and eyes closed $(\mathrm{p}=0.001, \mathrm{p}=0.001)$. Whereas females only displayed better static balance at the school age in the ML direction with eyes closed $(\mathrm{p}=0.050)$. (Table 3)

Within the single-leg stop-jump task, males at the school age displayed greater peak knee flexion angle $(p=0.011)$ than females. At the high school age, males demonstrated greater peak knee flexion angle $(p=0.011)$ and jump height $(\mathrm{p}<0.001)$ than females. (Table 4) Both males and females performed greater jump heights at the high school age compared to school age $(\mathrm{p}<0.001)$ and males showed greater vertical ground reaction forces at the high school age $(\mathrm{p}=0.034)$. (Table 4$)$ 
Table 2: Effects of age and sex on average isokinetic knee strength

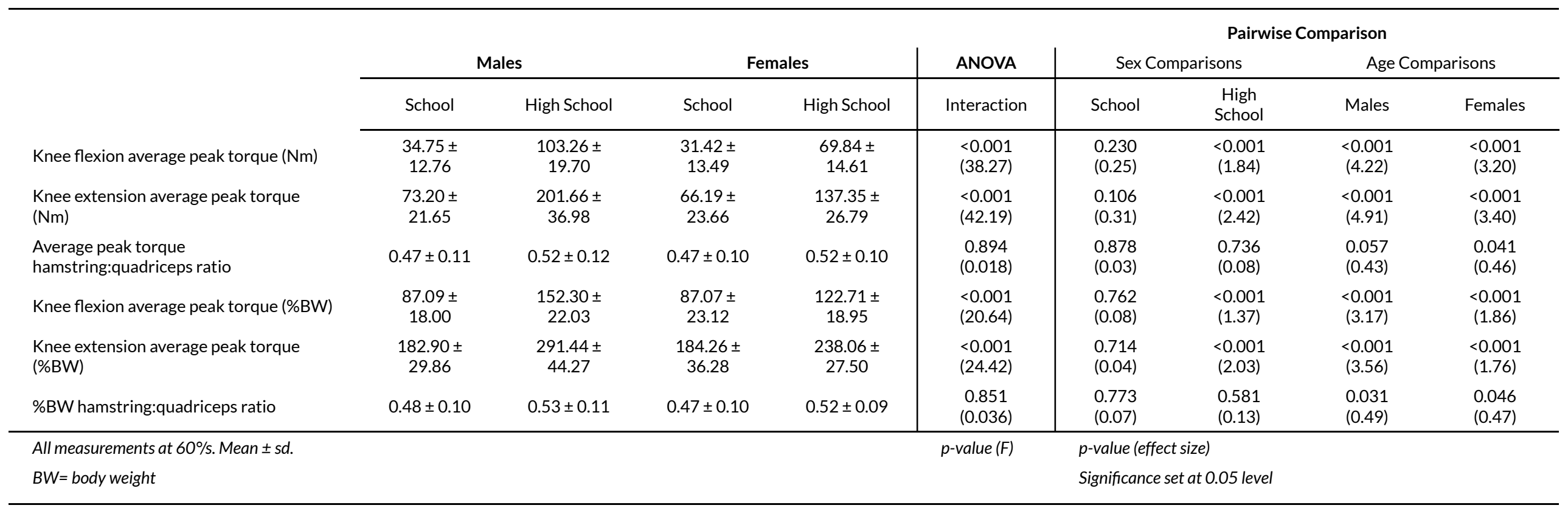


Table 3: Effects of age and sex on static balance ground reaction force standard deviation in eyes open and closed conditions

\begin{tabular}{|c|c|c|c|c|c|c|c|c|c|}
\hline & & & & & \multirow{3}{*}{$\frac{\text { ANOVA }}{\text { Interaction }}$} & \multicolumn{4}{|c|}{ Pairwise Comparison } \\
\hline & \multicolumn{2}{|c|}{ Males } & \multicolumn{2}{|c|}{ Females } & & \multicolumn{2}{|c|}{ Sex Comparisons } & \multicolumn{2}{|c|}{ Age Comparisons } \\
\hline & School & $\begin{array}{l}\text { High } \\
\text { School }\end{array}$ & School & $\begin{array}{c}\text { High } \\
\text { School }\end{array}$ & & School & $\begin{array}{l}\text { High } \\
\text { School }\end{array}$ & Males & Females \\
\hline $\begin{array}{l}\text { Eyes } \\
\text { open - } \\
\text { AP }\end{array}$ & $\begin{array}{c}2.16 \pm \\
1.12\end{array}$ & $\begin{array}{c}2.67 \pm \\
0.84\end{array}$ & $\begin{array}{c}1.72 \pm \\
0.80\end{array}$ & $\begin{array}{c}1.81 \pm \\
0.48\end{array}$ & $\begin{array}{l}0.112 \\
(2.55)\end{array}$ & $\begin{array}{l}0.047 \\
(0.44)\end{array}$ & $\begin{array}{c}<0.001 \\
(1.05)\end{array}$ & $\begin{array}{l}0.001 \\
(0.23)\end{array}$ & $\begin{array}{l}0.084 \\
(0.35)\end{array}$ \\
\hline $\begin{array}{l}\text { Eyes } \\
\text { open - } \\
\text { ML }\end{array}$ & $\begin{array}{c}2.71 \pm \\
1.57\end{array}$ & $\begin{array}{c}3.61 \pm \\
1.57\end{array}$ & $\begin{array}{c}2.12 \pm \\
1.20\end{array}$ & $\begin{array}{c}2.28 \pm \\
0.77\end{array}$ & $\begin{array}{l}0.081 \\
(3.09)\end{array}$ & $\begin{array}{l}0.018 \\
(0.42)\end{array}$ & $\begin{array}{c}<0.001 \\
(0.61)\end{array}$ & $\begin{array}{c}<0.001 \\
(0.26)\end{array}$ & $\begin{array}{l}0.066 \\
(0.20)\end{array}$ \\
\hline $\begin{array}{l}\text { Eyes } \\
\text { open - } \\
\text { V }\end{array}$ & $\begin{array}{c}4.53 \pm \\
3.08\end{array}$ & $\begin{array}{c}4.65 \pm \\
1.89\end{array}$ & $\begin{array}{c}3.75 \pm \\
2.55\end{array}$ & $\begin{array}{c}2.98 \pm \\
1.11\end{array}$ & $\begin{array}{l}0.221 \\
(1.51)\end{array}$ & $\begin{array}{l}0.200 \\
(0.27)\end{array}$ & $\begin{array}{c}<0.001 \\
(0.72)\end{array}$ & $\begin{array}{l}0.066 \\
(0.21)\end{array}$ & $\begin{array}{l}0.429 \\
(0.30)\end{array}$ \\
\hline $\begin{array}{l}\text { Eyes } \\
\text { closed } \\
\text { - AP }\end{array}$ & $\begin{array}{c}4.43 \pm \\
2.40\end{array}$ & $\begin{array}{c}5.49 \pm \\
1.65\end{array}$ & $\begin{array}{c}3.71 \pm \\
2.11\end{array}$ & $\begin{array}{c}3.87 \pm \\
1.11\end{array}$ & $\begin{array}{l}0.134 \\
(2.27)\end{array}$ & $\begin{array}{l}0.060 \\
(0.32)\end{array}$ & $\begin{array}{c}<0.001 \\
(1.25)\end{array}$ & $\begin{array}{l}0.001 \\
(0.45)\end{array}$ & $\begin{array}{l}0.079 \\
(0.19)\end{array}$ \\
\hline $\begin{array}{l}\text { Eyes } \\
\text { closed } \\
\text { - ML }\end{array}$ & $\begin{array}{c}6.72 \pm \\
3.39\end{array}$ & $\begin{array}{c}8.87 \pm \\
3.22\end{array}$ & $\begin{array}{c}5.35 \pm \\
3.10\end{array}$ & $\begin{array}{c}6.29 \pm \\
2.81\end{array}$ & $\begin{array}{l}0.233 \\
(1.43)\end{array}$ & $\begin{array}{l}0.027 \\
(0.42)\end{array}$ & $\begin{array}{c}<0.001 \\
(0.55)\end{array}$ & $\begin{array}{l}0.001 \\
(0.31)\end{array}$ & $\begin{array}{l}0.050 \\
(0.33)\end{array}$ \\
\hline $\begin{array}{l}\text { Eyes } \\
\text { closed } \\
-\mathrm{V}\end{array}$ & $\begin{array}{r}11.94 \\
\pm 7.59\end{array}$ & $\begin{array}{r}11.40 \\
\pm 4.42\end{array}$ & $\begin{array}{c}9.61 \pm \\
6.44\end{array}$ & $\begin{array}{c}8.63 \pm \\
5.50\end{array}$ & $\begin{array}{l}0.823 \\
(0.05)\end{array}$ & $\begin{array}{l}0.118 \\
(0.33)\end{array}$ & $\begin{array}{c}<0.001 \\
(0.41)\end{array}$ & $\begin{array}{l}0.692 \\
(0.23)\end{array}$ & $\begin{array}{l}0.700 \\
(0.15)\end{array}$ \\
\hline \multicolumn{5}{|c|}{$A P=$ anterior-posterior,$M L=$ medial-lateral,$V=$ vertical } & $p$-value (F) & \multicolumn{4}{|c|}{$p$-value (effect size) } \\
\hline Mean \pm & & & & & & \multicolumn{4}{|c|}{ Significance set at 0.05 level } \\
\hline
\end{tabular}

Table 4: Effects of age and sex on single leg stop jump knee joint angles, jump height and vertical ground reaction force

\begin{tabular}{|c|c|c|c|c|c|c|c|c|c|}
\hline & & & & & \multirow{3}{*}{$\frac{\text { ANOVA }}{\text { Interaction }}$} & \multicolumn{4}{|c|}{ Pairwise Comparison } \\
\hline & \multicolumn{2}{|c|}{ Males } & \multicolumn{2}{|c|}{ Females } & & \multicolumn{2}{|c|}{ Sex Comparisons } & \multicolumn{2}{|c|}{ Age Comparisons } \\
\hline & School & $\begin{array}{l}\text { High } \\
\text { School }\end{array}$ & School & $\begin{array}{l}\text { High } \\
\text { School }\end{array}$ & & School & $\begin{array}{c}\text { High } \\
\text { School }\end{array}$ & Males & Females \\
\hline $\begin{array}{l}\text { knee } \\
\text { flex@ } \\
\text { IC }\left(^{\circ}\right)\end{array}$ & $\begin{array}{r}14.55 \\
\pm 7.41\end{array}$ & $\begin{array}{r}11.96 \\
\pm 5.39\end{array}$ & $\begin{array}{r}13.89 \\
\pm 7.09\end{array}$ & $\begin{array}{r}12.54 \\
\pm 6.62\end{array}$ & $\begin{array}{l}0.559 \\
(0.34)\end{array}$ & $\begin{array}{l}0.689 \\
(0.09)\end{array}$ & $\begin{array}{l}0.669 \\
(0.39)\end{array}$ & $\begin{array}{l}0.078 \\
(0.68)\end{array}$ & $\begin{array}{l}0.388 \\
(0.04)\end{array}$ \\
\hline $\begin{array}{l}\text { knee } \\
A B / A D \\
@ I C\left(^{\circ}\right)\end{array}$ & $\begin{array}{c}2.83 \pm \\
8.07\end{array}$ & $\begin{array}{c}1.41 \pm \\
5.37\end{array}$ & $\begin{array}{c}2.48 \pm \\
7.78\end{array}$ & $\begin{array}{c}2.95 \pm \\
4.41\end{array}$ & $\begin{array}{l}0.369 \\
(0.81)\end{array}$ & $\begin{array}{l}0.849 \\
(0.04)\end{array}$ & $\begin{array}{l}0.849 \\
(0.13)\end{array}$ & $\begin{array}{l}0.237 \\
(0.08)\end{array}$ & $\begin{array}{l}0.873 \\
(0.01)\end{array}$ \\
\hline $\begin{array}{l}\text { peak } \\
\text { knee } \\
\text { flex }\left({ }^{\circ}\right)\end{array}$ & $\begin{array}{c}43.30 \\
\pm \\
11.54\end{array}$ & $\begin{array}{c}45.61 \\
\pm \\
11.53\end{array}$ & $\begin{array}{c}37.39 \\
\pm \\
10.68\end{array}$ & $\begin{array}{r}41.41 \\
\pm 9.27\end{array}$ & $\begin{array}{l}0.619 \\
(0.25)\end{array}$ & $\begin{array}{l}0.011 \\
(0.53)\end{array}$ & $\begin{array}{l}0.011 \\
(0.57)\end{array}$ & $\begin{array}{l}0.916 \\
(0.40)\end{array}$ & $\begin{array}{l}0.072 \\
(0.48)\end{array}$ \\
\hline $\begin{array}{l}\text { jump } \\
\text { height } \\
(\% \mathrm{BH})\end{array}$ & $\begin{array}{r}13.38 \\
\pm 3.98\end{array}$ & $\begin{array}{r}21.24 \\
\pm 2.88\end{array}$ & $\begin{array}{r}12.78 \\
\pm 3.50\end{array}$ & $\begin{array}{r}16.19 \\
\pm 2.82\end{array}$ & $\begin{array}{l}<0.001 \\
(17.67)\end{array}$ & $\begin{array}{l}0.238 \\
(0.16)\end{array}$ & $\begin{array}{c}<0.001 \\
(2.27)\end{array}$ & $\begin{array}{c}<0.001 \\
(2.66)\end{array}$ & $\begin{array}{c}<0.001 \\
(1.16)\end{array}$ \\
\hline $\begin{array}{l}\text { peak } \\
\text { vGRF } \\
\text { (\%BW) }\end{array}$ & $\begin{array}{c}3.48 \pm \\
0.72\end{array}$ & $\begin{array}{c}3.76 \pm \\
0.65\end{array}$ & $\begin{array}{c}3.63 \pm \\
0.76\end{array}$ & $\begin{array}{c}3.39 \pm \\
0.54\end{array}$ & $\begin{array}{l}0.015 \\
(6.03)\end{array}$ & $\begin{array}{l}0.395 \\
(0.20)\end{array}$ & $\begin{array}{l}0.395 \\
(0.42)\end{array}$ & $\begin{array}{l}0.034 \\
(0.28)\end{array}$ & $\begin{array}{l}0.285 \\
(0.32)\end{array}$ \\
\hline \multicolumn{5}{|c|}{$I C=$ intitial contact, $v G R F=$ vertical ground reaction force.} & $p$-value (F) & \multicolumn{4}{|c|}{$p$-value (effect size) } \\
\hline Mean $\pm s$ & & & & & & \multicolumn{4}{|c|}{ Significance set at 0.05 level } \\
\hline
\end{tabular}

\section{DISCUSSION}

Children and adolescents are subjected to a maturation process that is not linear, creating the need for periodic assessment to correctly define and change training programs. This study examined the effects chronological age and sex have on modifiable musculoskeletal and neuromuscular characteristics to help inform effective training programs. Unlike previous literature, the current study looked 
at multiple variables in the same participant. The results observed in this study predominantly supported the hypotheses. Differences after maturation were seen in strength, balance, and biomechanics. These findings showed increase in strength and jump performance in both sexes and decreases in male static balance as age increased. We saw limited differences between sexes at the school age. In this study, both sexes had a significant increase in height and weight through maturation, although high school aged male athletes were on average almost $15 \mathrm{~kg}$ heavier than their female counterpart (Table 1). With one-third of youth requiring medical attention for activity related injuries, it is essential to understand the effect of growth, development and sex related physiological differences on sports injury and performance. ${ }^{1}$ Development of muscular strength, balance and proper mechanics through age and sex appropriate interventions is essential for sustainable long-term athletic performance. Identifying neuromuscular differences between sexes and changes throughout maturation can help to develop specific training techniques to reduce the incidence of these injuries.

\section{ISOKINETIC KNEE STRENGTH}

Dynamic knee stability is essential in an athlete's safety while participating in activities that require cutting, jumping, and landing. Co-contraction of the hamstring and quadriceps muscles has been found to stabilize the knee 24 and an imbalance in hamstring to quadriceps strength may be of significance in non-contact leg injuries. ${ }^{25}$ The current study shows a significant increase in the ratio of hamstringto-quadriceps strength, normalized to body weight, from the school to high school age of male and female athletes but no difference between sex. This demonstrates that while the hamstrings and quadriceps of both sexes increased with age, hamstring strength increased to a greater extent. Previous work that found significant differences in hamstring-to-quadriceps strength ratio between sex in 9-12 year old. ${ }^{14}$ This may be due to their participants being children recruited from local schools rather than specifically using athletes as in the current study. In young soccer athletes, an significant increase in hamstring-to-quadriceps strength ratio was seen from immature to mature females but not in males. ${ }^{26}$

Moreover, knee stability is related to quadriceps and hamstring individual action at the knee; with quadriceps strength playing a vital role during landing to decelerate the body and absorb impact forces ${ }^{27}$ and the hamstrings controlling anterior tibial translation. ${ }^{28}$ It has been proposed that differences in muscular strength and sex specific neuromuscular activation patterns are one reason females have a greater risk of noncontact ACL injury. ${ }^{29}$ The current findings agree with previous research, that absolute and body weight corrected strength gains occur in both sexes after puberty and significant differences can be seen between sexes at the high school age (Table 2).${ }^{30}$ Parallel to the current findings, the Physical Activity Guidelines released from the federal government reported that both sexes significantly increase strength through maturation. Their data show adolescent boys and girls exerted significantly more pounds of force with knee extension than younger boys and girls. ${ }^{31}$ Similarly, significant increases in quadriceps and hamstring strength were seen with maturity in male and female soccer players. ${ }^{32}$ Barber-Westin et al. ${ }^{33}$ also found significant strength differences as chronological age increases. Thirteen-year-old female athletes were shown to have $20 \%$ greater knee extension peak torque than 9-year old, while 14-year-old male athletes had $38 \%$ greater peak torque than 9-year old. It was also found that no significant differences in knee extension or flexion peak torque exist between sexes until the age of 14 years. Male athletes between 14-17 years had significantly greater extension and flexion peak torque than their female counterparts. ${ }^{33}$ Data also aligns with current findings that no significant difference in strength were seen between younger girls and boys (age 6-11) for knee extension but they did find significant differences between adolescent girls and boys (age 12-15). ${ }^{31}$ Decrements in muscular strength have been associated with the lack of dynamic stability surrounding lower extremity joints, potentially resulting decreased balance ability.

\section{STATIC BALANCE GROUND REACTION FORCE}

Poor balance has been significantly associated with an increased risk of lower extremity injury. ${ }^{7,34}$ One measure is single leg static balance, requiring an athlete to minimize center of mass movement over a small base of support, ${ }^{35}$ is related to the unconscious neuromuscular control and stabilization of joints. ${ }^{36}$ Balance begins to emerge as a trainable motor skill from the age of 10,37 therefore this study evaluated static balance as a prerequisite to the additional coordination needed for dynamic balance. This study showed significant decreases in static balance in male athletes as they reached the high school age (Table 3). This may be due to the greater physical growth that occurs in males during puberty. Increases in body weight have been shown to cause a decrease in balance, due to changes in center of mass. ${ }^{38}$ During puberty, growth changes may happen at a faster rate than the visual, vestibular and somatosensory systems can adapt. Increases in body weight, without increase in neuromuscular control, may be the cause of the disturbances in equilibrium seen in high school aged males. To decrease risk of injury in male athletes during and after puberty, prophylactic balance training may lead to task-specific neural adaptations. ${ }^{39}$ Additionally, training to improve balance can decrease risk of injury by enhancing agonist-antagonist muscle co-contractions which increases joint stiffness, and stabilizing joints against perturbations. ${ }^{40}$ Similar to knee stability, balance requires swift and constant feedback from visual, vestibular and somatosensory systems for coordinated movement to maintain balance. ${ }^{41}$ This study shows that female athletes have significantly better medial-lateral stability at both age groups (Table 3). All static balance measures were also significantly different between sexes in the high school age group. These results may be due to a lower center of gravity in females compared to males. While not assessed in this study, if females had smaller and lighter upper body with larger and heavier lower body, compared to males, this would increase the stability of their center of gravity. A difference in static balance at the high school age compared to females and to males at the school age may also be the result of increased 
strength seen in this study. However, Granacher and Gollhofer 42,43 reported no significant associations between postural control and muscular strength. These current findings are consistent with previous literature that also revealed young females had significantly better static balance than males. ${ }^{44}$ Since balance and coordination are not fully matured in children, balance training is an important preparatory phase of athlete development for enhancing strength and power and reducing the risk of athletic injury.

\section{SINGLE LEG STOP-JUMP}

The vertical jump has been found to be a predictor of performance, running speed and agility. ${ }^{45}$ The neuromuscular spurt seen in adolescent boys throughout maturation causes increased power, strength and coordination. ${ }^{30}$ This growth spurt may explain why vertical jump height, a measure of whole body power, increases in boys during puberty but not usually in girls. Significant pubertal stage by sex interaction has been previously seen in maximum vertical jump height, with boys increasing jump height after puberty but not girls. ${ }^{16}$ However, the current study found a significant difference in both male and female athletes' jump height through maturation (Table 4). Increased jump height at the high school age may be related to the increase in muscular strength seen in both sexes at the high school age. Differences in jump height between sex at the high school age may be due to increased testosterone levels in males. Following puberty, males have 15 times higher circulating testosterone concentration than in females. ${ }^{46}$ The biological effects of elevated testosterone include larger muscle mass and stiffer connective tissue, allowing males to exert greater muscular force more rapidly. ${ }^{47,48}$ However, this study did not assess hormone or associated hemoglobin levels in participants. This study only showed significant differences in peak vertical ground reaction forces (GRF) between school-aged and high school aged male athletes. Increased vertical GRFs in males at the high school age may be due to the larger increase in vertical jump height. Although jump height significantly increased at the high school age for both sexes, on average, males jumped 8 inches higher than their school age counterparts, while females only jumped 4 inches higher. No difference in vertical GRF was found between sexes at the school or high school age (Table 4). This differs from Pappas et al. ${ }^{49}$ who found females to have greater vertical GRF during jump tests than is found in male athletes. However, current results are similar to previous research that found no vertical GRF difference between sexes, but did report differences in rate of loading in which females reached vertical GRF $20 \%$ faster than males. ${ }^{50}$ It was proposed that decreased knee flexion and neuromuscular response reduces the ability of females to attenuate forces when landing. Lack of differences between sexes at each age group may be related to the speed in which participants decelerated, which was not assessed in the current study. These findings of no differences between sexes in knee kinematics at initial contact may also be associated with similar GRF values for both sexes.

Single-leg landings occur frequently in physical activity and sports. Proper biomechanics during landing can affect ground reaction force and loading of lower extremity struc- tures, in turn preventing lower limbs injuries. ${ }^{51}$ This study showed no significant difference for either sex through maturation for knee flexion and abduction/adduction angles at initial or peak knee flexion angle during a single leg vertical stop jump task (Table 4). This is partially similar to Yu et $\mathrm{al}^{52}$ who found no difference between ages for knee flexion angle at initial contact or peak flexion angle in male soccer players during a stop-jump task. However, they did find significant decrease in both knee flexion angles for female soccer players as they aged. ${ }^{52}$

Initiating neuromuscular training in females at a younger age may help develop optimal movement strategies and mitigate the effects of puberty on dynamic control. As knee flexion angle increases, tensile stress on the ACL due to quadriceps muscle contraction has been shown to decrease. ${ }^{53}$ Neuromuscular training to develop hamstring and quadriceps co-contraction may protect the lower extremity during sport related movements. ${ }^{54}$ Significantly smaller peak knee flexion angles in females show the need for safe landing strategies, increasing knee flexion angle, at all ages. This may be related to muscle loading, which was not assessed in the current study. Decker et al. ${ }^{55}$ reported greater knee extensor and ankle plantarflexor energy absorption in females during drop jumps. This led to a more upright posture to maximize energy absorption at the hip and ankles. The current study did not find significant sex differences in knee flexion and abduction/adduction angle at initial contact in both the school aged and high school aged groups. Again, these results are similar to Yu et al. ${ }^{52}$ who also found that female youth soccer players had decreased knee flexion angles during a stop-jump task. Yet these results are different from previous findings that show knee valgus angle during landing to be greater in female athletes as compared to males. ${ }^{49}$ Increase in female knee valgus angles found in their study may be associated with the increase in female vertical GRF also seen in their study, neither of which were observed in the current study.

The current study had limitations, including the small sample size for each sex in the school aged and high school groups. Tanner staging by a trained health care professional has long been the medical standard. ${ }^{56}$ Therefore this study only included participants who self-assessed within stage 1 or stage 4 to reduce the chance of miscategorization. Additionally, athletes in this study did not participate in the same sport, but all athletes did participate in sports that require jumping, cutting and landing (ie: soccer or basketball) to represent the types of sports in which non-contact ACL injury can occur. Activity frequency was a component of inclusion criteria to ensure athletes had similar general sport training. Neuromuscular training has been shown to alter strength and biomechanics in adolescent girls. ${ }^{57}$ Continued analysis of this data set can look for associations between variables measured, to determine what the potential cause of age and sex related differences may be. Future research examining an age and sex specific training intervention would be beneficial in minimizing significant changes in balance and biomechanics from the school to high school age. 


\section{CONCLUSION}

There are a number of factors unique to the adolescent athlete during the period of growth and maturation that have the potential to increase injury risk. ${ }^{11}$ Examination of neuromuscular and biomechanical sex differences throughout growth and maturation may help identify risk factors that lead to injury rate differences. By assessing multiple factors within an individual participant, the current study gives a more comprehensive assessment of the athlete. This study showed significant increase in strength from school age to high school age in both sexes and that male athletes were significantly stronger at the high school age. Static balance was significantly better in male athletes at school age compared to high school aged. At the high school age, female athletes demonstrated significantly better static balance. Vertical stop jump height increased from the school age to the high school age in both sexes and peak knee flex- ion angles were greater in male athletes at both the school and high ages. Fitness and skill development occur on a constantly changing base of physical growth and biological maturation; these processes occur simultaneously and interact with each other and the demands of sport. It is important to understand how the role of sex and maturation influence athletic development for the most effective injury prevention and performance programs.

\section{CONFLICTS OF INTEREST}

The authors report no conflicts of interest related to this manuscript.

Submitted: March 03, 2020 CDT, Accepted: October 10, 2020

CDT 


\section{REFERENCES}

1. Hawkins D, Metheny J. Overuse injuries in youth sports: Biomechanical considerations. Med Sci Sports Exerc. 2001;33(10):1701-1707. doi:10.1097/0000576 8-200110000-00014

2. Ardern CL, Ekas G, Grindem H, et al. International Olympic Committee consensus statement on prevention, diagnosis and management of paediatric anterior cruciate ligament (ACL) injuries. Knee Surg Sports Traumatol Arthrosc. 2018.

3. Shea KG, Pfeiffer R, Wang JH, Curtin M, Apel PJ. Anterior cruciate ligament injury in pediatric and adolescent soccer players: An analysis of insurance data. J Pediatr Orthop. 2004;24(6):623-628. doi:10.109 7/01241398-200411000-00005

4. Stanley LE, Kerr ZY, Dompier TP, Padua DA. Sex differences in the incidence of anterior cruciate ligament, medial collateral ligament, and meniscal injuries in collegiate and high school sports: 2009-2010 through 2013-2014. Am J Sports Med. 2016;44(6):1565-1572. doi:10.1177/036354651663092 7

5. Zazulak BT, Hewett TE, Reeves NP, Goldberg B, Cholewicki J. Deficits in neuromuscular control of the trunk predict knee injury risk: A prospective biomechanical-epidemiologic study. Am J Sports Med. 2007;35(7):1123-1130. doi:10.1177/036354650730158 $\underline{5}$

6. Hewett TE, Myer GD, Ford KR. Anterior cruciate ligament injuries in female athletes: Part 1, mechanisms and risk factors. Am J Sports Med. 2006;34(2):299-311. doi:10.1177/0363546505284183

7. Oshima T, Nakase J, Kitaoka K, et al. Poor static balance is a risk factor for non-contact anterior cruciate ligament injury. Arch Orthop Trauma Surg. 2018;138(12):1713-1718. doi:10.1007/s00402-018-29 $\underline{84-\mathrm{Z}}$

8. Ameer MA, Muaidi QI. Relation between peak knee flexion angle and knee ankle kinetics in single-leg jump landing from running: A pilot study on male handball players to prevent ACL injury. Phys Sportsmed. 2017;45(3):337-343. doi:10.1080/0091384 7.2017.1344514

9. Myer GD, Chu DA, Brent JL, Hewett TE. Trunk and hip control neuromuscular training for the prevention of knee joint injury. Clin Sports Med. 2008;27(3):425-448, ix. doi:10.1016/j.csm.2008.02.00 $\underline{6}$
10. Malina RM, Bouchard C, Bar-Or O. Growth, Maturation, and Physical Activity. Champaign, IL: Human Kinetics; 2004. doi:10.5040/9781492596837

11. Engebretsen L, Steffen K, Bahr R, et al. The International Olympic Committee Consensus statement on age determination in high-level young athletes. Br J Sports Med. 2010;44(7):476-484. doi:1 0.1136/bjsm.2010.073122

12. Ford KR, Myer GD, Toms HE, Hewett TE. Gender differences in the kinematics of unanticipated cutting in young athletes. Med Sci Sports Exerc. 2005;37(1):124-129. doi:10.1249/01.mss.000015008 7.95953.c3

13. Raudsepp L, Pääsuke M. Gender differences in fundamental movement patterns, motor performances, and strength measurements of prepubertal children. Pediatr Exerc Sci. 1995;7(3):294-304. doi:10.1123/pes.7.3.294

14. Holm I, Vøllestad N. Significant effect of gender on hamstring-to-quadriceps strength ratio and static balance in prepubescent children from 7 to 12 years of age. Am J Sports Med. 2008;36(10):2007-2013. doi:1 $0.1177 / 0363546508317963$

15. Schmitz RJ, Shultz SJ, Nguyen AD. Dynamic valgus alignment and functional strength in males and females during maturation. Journal of athletic training. 2009;44(1):26-32. doi:10.4085/1062-6050-4 $\underline{4.1 .26}$

16. Quatman CE, Ford KR, Myer GD, Hewett TE. Maturation leads to gender differences in landing force and vertical jump performance: A longitudinal study. Am J Sports Med. 2006;34(5):806-813. doi:10.11 77/0363546505281916

17. Lephart SM, Abt JP, Ferris CM, et al. Neuromuscular and biomechanical characteristic changes in high school athletes: A plyometric versus basic resistance program. Br J Sports Med. 2005;39(12):932-938. doi:10.1136/bjsm.2005.019083

18. Abt JP, Sell TC, Laudner KG, et al. Neuromuscular and biomechanical characteristics do not vary across the menstrual cycle. Knee Surg Sports Traumatol Arthrosc. 2007;15(7):901-907. doi:10.1007/s00167-00 7-0302-3

19. Sell TC, Abt JP, Crawford K, et al. Warrior Model for Human Performance and Injury Prevention: Eagle Tactical Athlete Program (ETAP) Part I. J Spec Oper Med. 2010;10(4):2-21. 
20. Goldie PA, Bach TM, Evans OM. Force platform measures for evaluating postural control: Reliability and validity. Arch Phys Med Rehabil. 1989;70(7):510-517.

21. Goldie PA, Evans OM, Bach TM. Steadiness in one-legged stance: Development of a reliable forceplatform testing procedure. Arch Phys Med Rehabil. 1992;73(4):348-354. doi:10.1016/0003-9993(92)9000 $\underline{8-\mathrm{k}}$

22. Sell TC, Ferris CM, Abt JP, et al. The effect of direction and reaction on the neuromuscular and biomechanical characteristics of the knee during tasks that simulate the noncontact anterior cruciate ligament injury mechanism. Am J Sports Med. 2006;34(1):43-54. doi:10.1177/0363546505278696

23. Sell TC, Ferris CM, Abt JP, et al. Predictors of proximal tibia anterior shear force during a vertical stop-jump. J Orthop Res. 2007;25(12):1589-1597. do i:10.1002/jor.20459

24. Hsu A-T, Perry J, Gronley JK, Hislop HJ. Quadriceps force and myoelectric activity during flexed knee stance. Clin Orthop Relat Res. 1993;(288):254-262. doi:10.1097/00003086-19930300 $\underline{0-00032}$

25. Kim D, Hong J. Hamstring to quadriceps strength ratio and noncontact leg injuries: A prospective study during one season. Isokinet Exerc Sci. 2011;19(1):1-6. doi:10.3233/IES-2011-0406

26. Ahmad CS, Clark AM, Heilmann N, Schoeb JS, Gardner TR, Levine WN. Effect of gender and maturity on quadriceps-to-hamstring strength ratio and anterior cruciate ligament laxity. Am J Sports Med. 2006;34(3):370-374. doi:10.1177/036354650528 0426

27. Lephart SM, Ferris CM, Riemann BL, Myers JB, Fu FH. Gender differences in strength and lower extremity kinematics during landing. Clin Orthop Relat Res. 2002;401:162-169. doi:10.1097/00003086-2 00208000-00019

28. Draganich LF, Vahey JW. An in vitro study of anterior cruciate ligament strain induced by quadriceps and hamstrings forces. J Orthop Res. 1990;8(1):57-63. doi:10.1002/jor.1100080107

29. Peterson JR, Krabak BJ. Anterior cruciate ligament injury: Mechanisms of injury and strategies for injury prevention. Phys Med Rehabil Clin N Am. 2014;25(4):813-828. doi:10.1016/i.pmr.2014.06.010

30. Beunen G, Malina RM. Growth and physical performance relative to the timing of the adolescent spurt. Exerc Sport Sci Rev. 1988;16:503-540. doi:10.12 49/00003677-198800160-00018
31. Ervin RB, Wang CY, Fryar CD, et al. Measures of muscular strength in U.S. children and adolescents, 2012. NCHS Data Brief. 2013;(139):1-8.

32. Ahmad CS, Clark AM, Heilmann N, Schoeb JS, Gardner TR, Levine WN. Effect of gender and maturity on quadriceps-to-hamstring strength ratio and anterior cruciate ligament laxity. Am J Sports Med. 2006;34(3):370-374. doi:10.1177/036354650528 $\underline{0426}$

33. Barber-Westin SD, Noyes FR, Galloway M. Jumpland characteristics and muscle strength development in young athletes: A gender comparison of 1140 athletes 9 to 17 years of age. Am J Sports Med. 2006;34(3):375-384. doi:10.1177/0363546505281242

34. Tropp H, Ekstrand J, Gillquist J. Stabilometry in functional instability of the ankle and its value in predicting injury. Med Sci Sports Exerc. 1984;16(1):64-66. doi:10.1249/00005768-19840100 0-00013

35. Gribble PA, Hertel J, Plisky P. Using the Star Excursion Balance Test to assess dynamic posturalcontrol deficits and outcomes in lower extremity injury: A literature and systematic review. Journal of athletic training. 2012;47(3):339-357. doi:10.4085/106 2-6050-47.3.08

36. Schnurrer-Luke Vrbanić T, Ravlić-Gulan J, Gulan $\mathrm{G}$, et al. Balance index score as a predictive factor for lower sports results or anterior cruciate ligament knee injuries in Croatian female athletes-preliminary study. Coll Antropol. 2007;31(1):253-258.

37. Ricotti L. Static and dynamic balance in young athletes. Journal of human sport and exercise. 2011;6(4):616-628. doi:10.4100/jhse.2011.64.05

38. Hue O, Simoneau M, Marcotte J, et al. Body weight is a strong predictor of postural stability. Gait Posture. 2007;26(1):32-38. doi:10.1016/i.gaitpost.2006.07.005

39. Taube W, Gruber M, Gollhofer A. Spinal and supraspinal adaptations associated with balance training and their functional relevance. Acta Physiol (Oxf). 2008;193(2):101-116. doi:10.1111/j.1748-171 6.2008.01850.x

40. Lloyd DG. Rationale for training programs to reduce anterior cruciate ligament injuries in Australian football. J Orthop Sports Phys Ther. 2001;31(11):645-654; discussion 661. doi:10.2519/jos pt.2001.31.11.645

41. Hrysomallis C. Balance ability and athletic performance. Sports Med. 2011;41(3):221-232. doi:1 $\underline{0.2165 / 11538560-000000000-00000}$ 
42. Granacher U, Gollhofer A. Is there an association between variables of postural control and strength in adolescents? J Strength Cond Res.

2011;25(6):1718-1725. doi:10.1519/jsc.0b013e3181db $\underline{\mathrm{db} 08}$

43. Granacher U, Gollhofer A. Is there an association between variables of postural control and strength in prepubertal children? J Strength Cond Res.

2012;26(1):210-216. doi:10.1519/jsc.0b013e31821b7c $\underline{30}$

44. Lee AJ, Lin W-H. The influence of gender and somatotype on single-leg upright standing postural stability in children. J Appl Biomech.

2007;23(3):173-179. doi:10.1123/jab.23.3.173

45. Wisloff U, Castagna C, Helgerud J, et al. Strong correlation of maximal squat strength with sprint performance and vertical jump height in elite soccer players. Br J Sports Med. 2004;38(3):285-288. doi:10.1 136/bjsm.2002.002071

46. Bae YJ, Zeidler R, Baber R, et al. Reference intervals of nine steroid hormones over the life-span analyzed by LC-MS/MS: Effect of age, gender, puberty, and oral contraceptives. The Journal of steroid biochemistry and molecular biology. 2019;193:105409. $\underline{\text { doi:10.1016/i.jsbmb.2019.105409 }}$

47. Janssen I, Heymsfield SB, Wang ZM, Ross R. Skeletal muscle mass and distribution in 468 men and women aged 18-88 yr. J Appl Physiol. 2000;89(1):81-88. doi:10.1152/jappl.2000.89.1.81

48. Lepley AS, Joseph MF, Daigle NR, et al. Sex differences in mechanical properties of the achilles tendon: Longitudinal response to repetitive loading exercise. The Journal of Strength \& Conditioning Research. 2018;32(11):3070-3079. doi:10.1519/jsc.000 $\underline{0000000002386}$

49. Pappas E, Hagins M, Sheikhzadeh A, Nordin M, Rose D. Biomechanical differences between unilateral and bilateral landings from a jump: Gender differences. Clin J Sport Med. 2007;17(4):263-268. do i:10.1097/jsm.0b013e31811f415b
50. Abbasi A, Sadeghi H, Khaleghi M. Gender differences in vertical ground reaction force attenuation during stop-jump task. Paper presented at the: ISBS-Conference Proceedings Archive 2008.

51. Hewett TE, Myer GD, Ford KR, et al. Biomechanical measures of neuromuscular control and valgus loading of the knee predict anterior cruciate ligament injury risk in female athletes: A prospective study. Am J Sports Med. 2005;33(4):492-501. doi:10.1177/0363546504269591

52. Yu B, McClure SB, Onate JA, Guskiewicz KM, Kirkendall DT, Garrett WE. Age and gender effects on lower extremity kinematics of youth soccer players in a stop-jump task. Am J Sports Med. 2005;33(9):1356-1364. doi:10.1177/036354650427304 9

53. Beynnon B, Howe JG, Pope MH, Johnson RJ, Fleming BC. The measurement of anterior cruciate ligament strain in vivo. Int Orthop. 1992;16(1):1-12. $\underline{\mathrm{d}}$ oi:10.1007/bf00182976

54. Myer GD, Ford KR, Barber Foss KD, Liu C, Nick TG, Hewett TE. The relationship of hamstrings and quadriceps strength to anterior cruciate ligament injury in female athletes. Clin J Sport Med. 2009;19(1):3-8. doi:10.1097/ism.0b013e318190bddb

55. Decker MJ, Torry MR, Wyland DJ, Sterett WI, Richard Steadman J. Gender differences in lower extremity kinematics, kinetics and energy absorption during landing. Clinical Biomechanics. 2003;18(7):662-669. doi:10.1016/s0268-0033(03)0009 $\underline{0-1}$

56. Koopman-Verhoeff ME, Gredvig-Ardito C, Barker DH, Saletin JM, Carskadon MA. Classifying pubertal development using child and parent report: Comparing the pubertal development scales to Tanner staging. J Adolesc Health. 2020;66(5):597-602. doi:10.1016/i.jadohealth.2019.11.308

57. Myer GD, Ford KR, Palumbo JP, et al. Neuromuscular training improves performance and lower-extremity biomechanics in female athletes. $J$ Strength Cond Res. 2005;19(1):51-60. 